\title{
Resistance studies of erythromycin and rifampin for Rhodococcus equi over a 10-year period
}

\author{
T. Buckley, E. McManamon and S. Stanbridge \\ Irish Equine Centre, Johnstown, Naas, Co. Kildare, Ireland
}

\author{
Corresponding author: \\ T. Buckley, \\ Irish Equine Centre, Johnstown, Naas, Co. Kildare, Ireland \\ Email: tbuckley@equine-centre.ie \\ Tel: +35345866266 \\ Fax: +35345866 701
}

\begin{abstract}
This study sought to determine whether an increase in resistance of Rhodococcus equi to the antibiotics rifampin and erythromycin occurred over a 10-year period. This was carried out by the use of E test strips for rifampin and erythromycin to determine the MIC (minimum inhibitory concentration) values of Rhodococcus equi to this combination of antibiotics.

The findings of this study indicated that there was an increase in resistance of Rhodococcus equi to rifampin and erythromycin over the 10 -year period. The MIC for rifampin increased from $0.081 \mu \mathrm{g} / \mathrm{ml}$ in 1996 to $0.187 \mu \mathrm{g} / \mathrm{ml}$ in 2006 and from $0.258 \mu \mathrm{g} / \mathrm{ml}$ for erythromycin during the years prior to 2000 to $0.583 \mu \mathrm{g} / \mathrm{ml}$ in 2006 .

This finding suggests that there may be a problem in the treatment of Rhodococcus equi infections in foals in the future, particularly as the number of drugs available for treatment of Rhodococcus equi infection is limited because of the intracellular capabilities of this bacterium. Antibiotics used in its treatment have to be able to penetrate the polysaccharide cell wall of Rhodococcus equi as well as the alveolar macrophages in which the bacterium is capable of surviving.
\end{abstract}

Key words: antibiotic, erythromycin, foals, Rhodococcus equi, rifampin, resistance

$\underline{\text { Irish Veterinary Journal }}$ Volume 60 Number 12, 728-731, 2007

\section{Introduction}

Rhodococcus equi is a facultative, intracellular, nonmotile, non-spore-forming, Gram-positive cocco-bacillus (Kedlaya and Ing, 2007). The bacterium has the name Rhodococcus because of its ability to form a red (salmon coloured) pigment. Rhodococcus equi was previously called Corynebacterium equi and currently is grouped with the aerobic actinomycetes (Kedlaya and Ing, 2007). Rhodococcus equi organisms most often induce chronic bronchopneumonia in young foals (Bertone et al., 1998). Rhodococcus equi can also cause other clinical conditions such as intestinal disease, non-specific synovitis and sporadic abscesses, but these syndromes are not as common as the pneumonic syndrome. Rhodococcus equi-associated bronchopneumonia of young foals was originally identified in 1923 (Bertone et al., 1998). Rhodococcus equi is largely a soil organism with simple growth requirements, which appear to be met perfectly by herbivore manure and summer temperatures in temperate climates (Prescott, 1991). Farms used for foal breeding over many years may thus become particularly dangerous for foals (Prescott, 1987).
Rhodococcus equi, although not the most common cause of pneumonia in foals from one to five months of age, has significant economic consequences due to mortality, prolonged treatment, surveillance programmes for early detection and relatively expensive prophylactic strategies (Prescott and Baggott, 1993). The susceptibility of foals under six months of age to respiratory infections may be due to a number of factors, including: immunodeficiency; overcrowding; heavy parasite burden; poor nutritional status; and heat stress (Prescott, 1993). There may also be a genetic basis for foal susceptibility to Rhodococcus equi infection based on the type of transferrin, an iron-binding protein that has bacteriostatic properties, in the blood (Mousel et al., 2003). Also, only certain types of Rhodococcus equi are pathogenic: those that contain virulence-associated protein A -Vap A. (Giguere et al., 1999). Rhodococcus equi pneumonia can progress to severe and extensive lung involvement prior to the development of clear clinical signs (Bertone et al., 1998). Of the many bacterial and viral agents that can cause foal pneumonia, Rhodococcus equi is one of the most difficult to treat but has been shown 


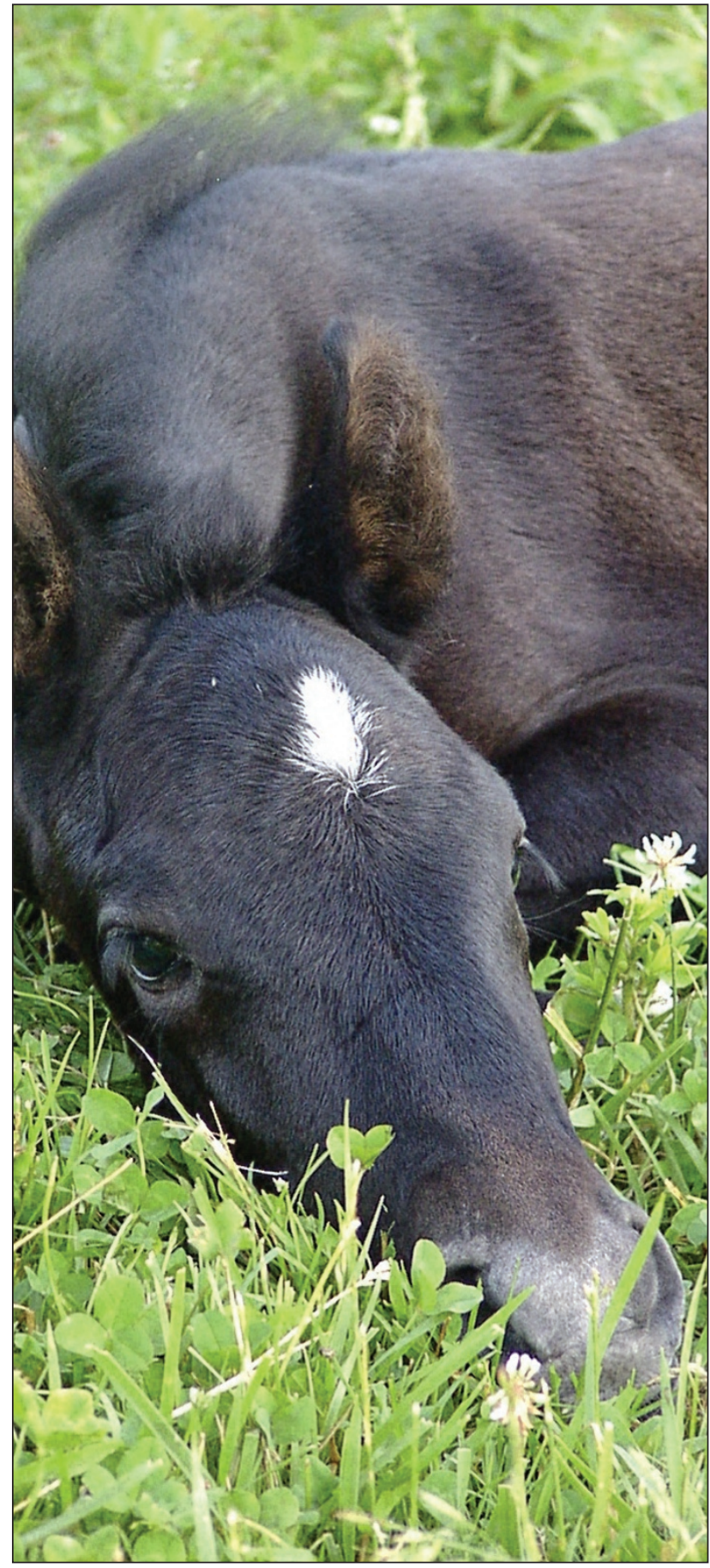

Figure 1: Rhodococcus equi organisms most often induce chronic bronchopneumonia in young foals.

to leave no residual lung damage following recovery

(Ainsworth et al., 1993) and have no lasting affect on future racing performance (Ainsworth et al., 1998).

Rhodococcus equi was previously thought to be exclusively an equine pathogen, but in recent years Rhodococcus equi infection is occurring with increasing frequency in humans (Prescott, 1991). Infection in a human was first reported in 1967 in a 29-year-old man with plasma cell hepatitis receiving immunosuppressant medications (Kedlaya and Ing, 2007). It is found exclusively in immunocompromised individuals, such as those with AIDS, small cell carcinoma of the lung, malignant lymphoma, or recipients of kidney or bone marrow transplants (Todar, 2002).

The organism is particularly susceptible to erythromycin and clindamycin; the aminoglycosides, amikacin, gentamycin, neomycin and tobromycin, rifampin and vancomycin (Prescott, 1991). It is moderately susceptible to penicillin G, ampicillin and tetracyclines, and is usually moderately susceptible or resistant to first and second generation cephalosporins (Prescott, 1991).

\section{As determined by FIC (fractional inhibitory}

concentration) indices, four combinations were synergistic: rifampin-erythromycin, rifampin-minocycline, erythromycin-minocycline and imipenem-amikacin (Nordmam and Roncon, 1992). Standard therapy involves the use of a combination of erythromycin and rifampin (Bertone et al., 1998). In order to treat Rhodococcus equi infection successfully, it is necessary to select an antibiotic which is not only effective against the organism in vitro, but which also has good distribution and activity in the lungs, with the ability to penetrate and sterilise caseous abscess cavities and to kill Rhodococcus equi organisms within neutrophils and macrophages (Hillidge, 1987). By using the combination of erythromycin and rifampin, not only are these drugs highly effective in vitro, they also penetrate macrophages well and have been shown to have additive and often synergistic activity in vitro (Prescott, 1991).

Erythromycin is a member of the macrolide group of antibiotics; it selectively inhibits protein synthesis in a broad range of bacteria by binding to the $50 \mathrm{~S}$ subunit of the bacterial ribosome (Todar, 2002). Resistance to erythromycin can occur by methylation of different bases within the same region of the 23S rRNA (Todar, 2002). Erythromycin also blocks translation.

Rifampin is the most important synthetically modified member of the family of the rifamycins, antibiotic products of Streptomyces mediterranei (Prescott and Baggot, 1993). It is always combined with other antibiotics because of the ready development of resistance to the drug (Prescott and Baggot, 1993). Rifampin has the unique action among antibiotics of inhibiting RNA polymerase, the enzyme that catalyses the transcription of DNA to RNA (Prescott and Baggot, 1993). Rifampin binds to the beta subunit of the enzyme and causes abortive initiation of RNA synthesis (Prescott and Baggot, 1993). Rifampin is a bactericidal antibiotic with a wide spectrum of antimicrobial activity including activity against Gram-positive bacteria and anaerobes and some antiviral and antifungal activity (Prescott and Baggot, 1993). An attractive feature of rifampin is its ability to kill intracellular bacteria (Prescott and Baggot, 1993).

Dosages for the erythromycin-rifampin combination range from $5-10 \mathrm{mg} / \mathrm{kg}$ orally one- to two-times daily for rifampin to $10-37.5 \mathrm{mg} / \mathrm{kg}$ orally two- to four-times daily for erythromycin (Bertone et al., 1998). 
The length of treatment depends on the clinical response, the return of the complete blood count and fibrinogen concentrations to normal and the resolution of radiographic and ultrasonographic abnormalities (Bertone et al., 1998). Treatment can last anything from 30 to 60 days, depending on the recovery of the foal.

Although the combination of rifampin and erythromycin has been used in the treatment of $R$. equi infection of foals for many years, adverse effects to treatment can occur, including hyperthermia, tachypnoea and, in rare circumstances, severe diarrhoea. In addition, occasional reports of resistance of $R$. equi to rifampin and erythromycin have been published over the last number of years (Kenney et al., 1994; Takai et al., 1997; Fines et al., 2001).

This study sought to determine whether an increase in resistance of Rhodococcus equi to the antibiotics rifampin and erythromycin occurred over a 10 -year period.

\section{Materials and methods}

Ninety-four Rhodococcus equi isolates, each isolated from clinical cases of Rhodococcus equi pneumonia over a period of 10 years (1996-2006), were stored in cooked meat medium at $-80^{\circ} \mathrm{C}$. The isolates of Rhodococcus equi were analysed for their MIC values to rifampin and erythromycin over a 10-year period using E test strips (PDM Epsilometer; AB Biodisk, Solna, Sweden) of each of the two antibiotics. The range of the strips used was $0.002-32 \mu \mathrm{g} / \mathrm{ml}$ for rifampin and $0.016-256 \mu \mathrm{g} / \mathrm{ml}$ for erythromycin. The zones of inhibition showed by each of the isolates of Rhodococcus equi were clear and easily readable. ATCC (American Type Culture Collection) control strains were used throughout the study. These showed sensitivity at a low concentration.

\section{Results}

A total of 94 samples of Rhodococcus equi were analysed for their MIC values to rifampin and erythromycin over a 10 -year period using E test strips of each of the two antibiotics. The samples were grouped according to the year in which they were detected and isolated within the Irish Equine Centre. The range of each of the antibiotic strips was $0.002-32 \mu \mathrm{g} / \mathrm{ml}$ for rifampin and $0.016-256 \mu \mathrm{g} / \mathrm{ml}$ for erythromycin.

Table 1: Means and ranges of the MIC concentration of Rhodococcus equi to rifampin and erythromycin for each year $(\mu \mathrm{g} / \mathrm{ml})$

\begin{tabular}{|l|l|l|}
$\begin{array}{l}\text { Year of sample } \\
\text { (No. of samples } \\
\text { tested) }\end{array}$ & Rifampin (range) & Erythromycin (range) \\
\hline $2006(12)$ & $0.187(0.12-1.00)$ & $0.583(0.50-0.75)$ \\
\hline $2005(10)$ & $0.181(0.12-0.64)$ & $0.496(0.25-0.75)$ \\
\hline $2004(10)$ & $0.142(0.12-0.25)$ & $0.333(0.25-0.50)$ \\
\hline $2003(10)$ & $0.137(0.03-0.25)$ & $0.348(0.25-0.50)$ \\
\hline $2002(11)$ & $0.132(0.03-0.25)$ & $0.400(0.25-0.38)$ \\
\hline $2001(11)$ & $0.125(0.12-0.12)$ & $0.265(0.12-0.38)$ \\
\hline $2000(10)$ & $0.114(0.04-0.19)$ & $0.233(0.19-0.38)$ \\
\hline Pre-2000 (20) & $0.081(0.03-0.12)$ & $0.258(0.12-0.38)$ \\
\hline
\end{tabular}

As can be seen in Table 1, it is clear that there was a marked increase in the MIC concentration of Rhodococcus equi to the antibiotic rifampin. This is shown as an increase of the MIC from $0.081 \mu \mathrm{g} / \mathrm{ml}$ pre-2000 to $0.187 \mu \mathrm{g} / \mathrm{ml}$ in 2006. This is a major increase in MIC concentration for any bacterium, especially Rhodococcus equi, because of the difficulties in its treatment. There is also a notable increase in the MIC concentration of Rhodococcus equi to erythromycin. This increase is not as extreme as for rifampin but its increase nevertheless is noteworthy; it increased from $0.258 \mu \mathrm{g} / \mathrm{ml}$ from pre-2000 to $0.583 \mu \mathrm{g} / \mathrm{ml}$ in 2006.

\section{Discussion}

The MIC concentrations of rifampin to Rhodococcus equi increased from $0.081 \mu \mathrm{g} / \mathrm{ml}$ pre-2000 to $0.187 \mu \mathrm{g} / \mathrm{ml}$ in 2006. This is a marked increase in MIC concentration for any bacterial pathogen, including Rhodococcus equi. If the trend of increasing resistance continues at the same rate, the bacterium may soon be completely resistant to this antibiotic and new methods of treatment may have to be used. Low levels of resistance are $2-8 \mu \mathrm{g} / \mathrm{ml}$ and high levels of resistance are $>128 \mu \mathrm{g} / \mathrm{ml}$ (Fines et al., 2001).

The MIC concentrations of erythromycin to Rhodococcus equi increased from $0.258 \mu \mathrm{g} / \mathrm{ml}$ pre-2000 to $0.583 \mu \mathrm{g} / \mathrm{ml}$ in 2006. This is also a large increase in MIC concentration representing an increase of $0.238 \mu \mathrm{g} / \mathrm{ml}$ over a 10 -year period. No resistant strains or samples of Rhodococcus equi to erythromycin were detected during this experiment and all of the samples were within the range reported by Prescott (1991). There is, however, a steadily increasing trend of resistance occurring in Rhodococcus equi to erythromycin and this increase may cause serious future problems in the treatment of Rhodococcus equi foal pneumonia. There is also evidence of resistance in the area of human medicine to these antibiotics (Asoh et al., 2003).

The consequence of these findings is that there is an inevitable resistance occurring in Rhodococcus equi to rifampin and erythromycin and that, in the future, these antibiotics may be less effective in the treatment of foal pneumonia caused by Rhodococcus equi. Because of this, the antibiotics azithromycin and clarithromycin have been proposed as alternatives to erythromycin and rifampin for the treatment of Rhodococcus equi infections in foals. They are more chemically stable, have a greater bioavailability and achieve higher concentrations in phagocytic cells and tissues than erythromycin (Jacks et al., 2003). Also, persistence of high concentrations of azithromycin in bronchoalveolar cells after discontinuation of administration suggests that a shorter dosage regime may be applied (Jacks et al., 2001).

\section{Conclusion}

The overall conclusion is that there is an increase in resistance occurring in Rhodococcus equi to the antibiotics commonly used in its treatment; rifampin 
and erythromycin. MIC concentrations of each of these antibiotics to the bacterium were determined over a 10-year period and a steady increase recorded for both antimicrobial agents.

\section{References}

Ainsworth, D.M., Beck, K.A., Bootwright, C.E., Snedden, K.A. and Reubbun, W.C. (1993). Lack of residual lung damage in horses in which Rhodococcus equi induced pneumonia has been diagnosed. American Journal of Veterinary Research 54: (12) 2115-2120.

Ainsworth, D.M., Eicker, S.W., Yeagar, A.E., Sweeney, C.R., Viel, L., Tesarowski, D., Lavoie, J.P., Hoffman, A., Paradis, M.R., Reed, S.M., Erb, H.N., Davidow, E. and Nalevanko, M. (1998). Associations between physical examination, laboratory and radiographic findings and outcome and subsequent racing performance of foals with Rhodococcus equi infection: 115 cases (1984-1992). Journal of American Veterinary Medical Association 213: (4) 510-515.

Asoh, N., Watanabe, H., Fines-Guyon, M., Watanabe, K., Oishi, K., Kositsakulchai, W., Sanchai, T., Kunsuikmengrai, K., Kahintapong, S., Khantawa, B., Tharavichitkul, P., Sirisanthana, T. and Nagatake, T. (2003). Emergence of rifampin-resistant Rhodococcus equi with several types of mutations in the rpoB gene among AIDS patients in Northern Thailand. Journal of Clinical Microbiology 41: (6) 2337-2340.

Bertone, J.J., Reed, S.M. and Bayly, W.M. (1998). Pneumonia and other disorders associated with Rhodococcus equi. In: Equine Internal Medicine, W.B. Saunders, London, p970-979.

Fines, M., Pronost, S. and Maillard, K. (2001). Characterization of mutations in the rpoB gene associated with rifampin resistance in Rhodococcus equi isolated from foals. J. Clin. Microbiol. 39: 2784-2787. Giguere, S., Hondalus, M.K., Yager, J.A., Darrah, P. and Prescott, J.F. (1999). Role of the 85-kilobase plaemis and plasmid encoded virulence associated protein A in intracellular survival and virulence in Rhodococcus equi. Infect. Immun. 67: (7) 3548-3557.

Hillidge, C.J. (1987). Use of erythromycin-rifampin combination in treatment of Rhodococcus equi pneumonia. Veterinary Microbiology 14: 337-342.

Jacks, S., Giguere, S., Gronwall, P.R., Brown, M.P. and Merritt, K.A. (2001). Pharmacokinetics of azithromycin and concentration in body fluids and bronchoalveolar cells in foals. American Journal of Veterinary Research 62: (12), 1870-1875.

Jacks, S.S., Giguere, S. and Nguyen, A. (2003). In vitro susceptibilities of Rhodococcus equi and other common equine pathogens to azithromycin, clarithromycin and 20 other antimicrobials. Antimicrobials Agents and Chemotherapy 47: (5) 1742-1745.

Kedlaya, I. and Ing, M. (2007). Rhodococcus equi [Online]. Available from: www.emedicine.com/med/topic3378.htm.

Kenney, D.G., Robbins, S.C. and Prescott, J.F. (1994). Development of reactive arthritis and resistance to erythromycin and rifampin in a foal during treatment for Rhodococcus equi pneumonia. Equine Vet. J. 26: 246248.

Mousel, M.R., Harrison, L., Dinahue, J.M. and Bailey, E. (2003).

Rhodococcus equi and genetic susceptibility: assessing transferring genotypes from paraffin-embedded tissues. Journal of Veterinary Diagnostic Investigation 15: (5) 470-472.

Nordmam, P. and Roncon, E. (1992). In-vitro antimicrobial susceptibility of Rhodococcus equi. Journal of Antimicrobial Chemotherapy 29: 383-393.

Prescott, J.F. (1987). Epidemiology of Rhodococcus equi infection in horses. Veterinary Microbiology 14: (3) 211-214.
Prescott, J.F. (1991). Rhodococcus equi: an animal and human pathogen. Clinical Microbiology Reviews 4: (1) 20-34.

Prescott, J.F. (1993). Immunodeficiency and serious pneumonia in foals: the plot thickens. Equine Veterinary Journal 25: 289-292.

Prescott, J.F. and Baggot, J.D. (1993). Antimicrobial Therapy in Veterinary Medicine ( $2^{\text {nd }}$ edn.). Iowa State University Press, Iowa.

Takai, S., Nakano, Y. and Karasawa, T. (1997). Emergence of rifampinresistant Rhodococcus equi in an infected foal. J. Clin. Microbiol. 35: 19041908.

Todar, K. (2002). Antimicrobial agents used in treatment of infectious disease. [Online]. Available from: http://textbookofbacteriology.net/ antimicrobial.html. 